\title{
Tuning the shape of ceria nanomaterials for catalytic applications
}

\author{
TA Na a, LIU (Jimmy) Jingyue b,a, \#, SHEN Wenjie a,* \\ a State Key Laboratory of Catalysis, Dalian Institute of Chemical Physics, Chinese Academy of Sciences, Dalian 116023, Liaoning, China \\ b Department of Physics, Arizona State University, Tempe, Arizona 85287, USA
}

\section{A R T I C L E I N F O}

Article history:

Received 21 February 2013

Accepted 21 March 3013

Published 20 May 2013

\section{Keywords:}

Cerium dioxide

Shape control

Nanorod

Nanotube

Nanocube

Crystal facet

Gold-ceria interface

Nanocatalysis

\begin{abstract}
A B S T R A C T
The design and fabrication of catalytic materials is a key issue in heterogeneous catalysis to achieve desired performance. Traditionally, the main theme is to reduce the size of the catalyst particles as small as possible for increasing the number of active sites. In recent years, the rapid advancement in materials science has enabled us to fabricate catalyst particles with tunable shape at nanometer level. Through morphology control of nanoparticles by exposing highly reactive crystal planes, their catalytic properties can be drastically enhanced. Therefore, both size modulation and shape control of catalyst nanoparticles can be achieved independently or synergistically to optimize their catalytic behavior. We highlight, in this review, the recent progress in shape control of $\mathrm{CeO}_{2}$ materials that are widely used as crucial components or structural and electronic promoters in heterogeneous catalysts. We first summarize the major synthetic strategies and characteristics of shape-controlled $\mathrm{CeO}_{2}$ nanomaterials. We then survey morphology-dependent nanocatalysis of $\mathrm{CeO}_{2}$ and $\mathrm{Au}-\mathrm{CeO}_{2}$ catalysts. We understand now that the enhanced catalytic property of the $\mathrm{Au}-\mathrm{CeO}_{2}$ system is closely related to the unique interaction between the gold nanoparticles and the ceria support; such an interaction originates from the particular shape of ceria, especially the exposed facets. Finally, we present our understanding of the morphology-dependent nanocatalysis and provide our perspectives on their future potential and development. The fundamental understanding of the nature of the intrinsic active sites of the shape-tunable ceria nanostructures, enclosed by reactive crystal planes/facets with unique properties, is expected to provide highly efficient nanocatalysts for practical applications.
\end{abstract}

(C) 2013, Dalian Institute of Chemical Physics, Chinese Academy of Sciences. Published by Elsevier B.V. All rights reserved.

\section{Morphology-dependent nanocatalysis}

Nanocatalysis is an explosively growing field because of its utmost important contributions to both the materials science and the practical chemical reactions. Because the property of a catalyst particle intimately depends on its size and shape, rational design and sophisticated fabrication of catalytic nanomaterials have become top priority in heterogeneous catalysis. Conventionally, an active catalyst typically contains small par- ticles where the percentage of the corner, step, and edge atoms increases with decreasing crystal sizes, facilitating the activation of the reactants [1-3]. A heterogeneous catalyst often consists of tiny single or twinned crystals, and their average sizes are usually less than $5-10 \mathrm{~nm}$ and can be as small as $1 \mathrm{~nm}$ in diameter. The catalytic performance of these nanosized particles is extremely sensitive to the surface structural and/or electronic properties [2,4]. Small particles with high surface-to-volume ratios provide more active sites which usually

\footnotetext{
* Corresponding author. Tel: +86-411-84379085; Fax: +86-411-84694447; E-mail: shen98@dicp.ac.cn

\# Corresponding author. Tel/Fax: +01-480-965-9731; E-mail: jingyue.liu@asu.edu

This work was supported by the National Natural Science Foundation of China (20923001, 21025312, and 21103172).

DOI: 10.1016/S1872-2067(12)60573-7 | http://www.sciencedirect.com/science/journal/18722067 | Chin. J. Catal., Vol. 34, No. 5, May 2013
} 
consist of low-coordinated atoms that are located at the defect sites such as terraces, edges, kinks, or vacancies. A typical example is the unique behavior of gold nanoparticles as demonstrated by the pioneering work of Haruta [5-9]. Gold has long been viewed as catalytically inert; however, it becomes highly active for low-temperature $\mathrm{CO}$ oxidation when the size of the Au particles ranges $2-5 \mathrm{~nm}[5,6]$. This so-called size effect has been interpreted in terms of the variation in geometric and/or electronic properties of gold nanoparticles that strongly affect the adsorption and activation of $\mathrm{CO}$ and molecular oxygen [9].

On the other hand, the catalytic property of a metal particle was also observed to be correlated with its shape at the nanometer level [10-12]. The stable shape of a catalyst particle primarily depends on the minimization of its total energy; the surface planes/facets of the particle strongly influence the particle's catalytic reactivity. Such a phenomenon is termed as shape- or morphology-dependent nanocatalysis: a particle with anisotropic shape promotes the efficiency of its catalytic reaction by selectively exposing more reactive crystal planes. In this context, platinum nanoparticles have been intensively studied and the relationship between the internal and external crystal structures of the nanocrystals and their catalytic behavior have been comprehensively addressed [13-21]. When being used to catalyze electron-transfer reaction between hexacyanoferrate ions and thiosulfate ions, the tetrahedral Pt particles, which consist primarily of $\{111\}$ facets, showed the highest activity whereas the cubic particles, which consist primarily of $\{100\}$ facets, exhibited the lowest activity [13-15]. Although the observed catalytic activity was originally correlated to the fraction of surface atoms located on the corners and edges of the nanoparticles [14], this result has clearly confirmed that the shape of a catalyst particle significantly affected the reaction efficiency. Similarly, tetrahexahedral Pt nanocrystals enclosed by high-index facets such as $\{730\},\{210\}$, and $\{520\}$ planes having a large density of atomic steps and dangling bonds offered a much higher activity for electro-oxidation of formic acid and ethanol than the octahedral particles exposing low-index planes such as $\{111\},\{100\}$, and $\{110\}$ [16]. In addition to modulating the activity, the shape of a platinum particle also mediates the selectivity of chemical reactions. Both surface analyses and experimental studies have evidenced that the (100) plane of a Pt nanoparticle only produced cyclohexane in benzene hydrogenation, but both cyclohexene and cyclohexane can formed on the (111) plane $[17,18]$. Therefore, we can conclude that tuning the shape of a catalyst particle can tailor its activity and selectivity through the change of binding energies which originates from the modification of surface geometrical and electronic properties [21].

Such a morphology-dependent catalytic behavior has been applied to metal oxide particles as well. Compared with the conventional spherical particles, $\mathrm{Co}_{3} \mathrm{O}_{4}$ nanorods exhibited surprisingly high activity for low-temperature CO oxidation [22]. The origin of this shape-dependent effect was traced back to the fact that the $\mathrm{Co}_{3} \mathrm{O}_{4}$ nanorods preferentially exposed more of the reactive $\{110\}$ planes, which contain large amounts of octahedrally coordinated $\mathrm{Co}^{3+}$ species, the active sites for $\mathrm{CO}$ oxidation. Similarly, quasicubic $\alpha-\mathrm{Fe}_{2} \mathrm{O}_{3}$ enclosed by six equiv- alent $\{110\}$ planes catalyzed CO oxidization at a much lower temperature than the flowerlike, hollow, or other forms of irregular external morphologies exposing various crystal planes [23]. $\mathrm{Cu}_{2} \mathrm{O}$ nanomaterials also showed a notable morphology-dependent phenomenon in CO oxidation [24] and in photodegradation of methyl orange [25] due to the selective exposure of high-index crystal planes. In most cases, the shape of the oxide particles, determined by the exposed crystal planes, affects their catalytic reactivity more remarkably than the commonly considered parameters such as the particle size and the surface area.

Cerium dioxide is one of the most important oxides as a crucial component or as a structural and electronic promoter in heterogeneous catalysts [26]. It typically acts as an oxygen buffer in the three-way catalysts for eliminating vehicle exhausts. Because of this most important technological application, both the materials science and the heterogeneous catalysis communities have focused extensive investigations on this material. The unique properties of $\mathrm{CeO}_{2}$ primarily originate from the quick and reversible redox cycle between $\mathrm{Ce}^{4+}$ and $\mathrm{Ce}^{3+}$ in the fluorite lattice, through which the oxygen in gas phase can easily transfer into the solid surface where the chemical reaction occurs. Accordingly, $\mathrm{CeO}_{2}$ has been considered as an excellent oxygen buffer, commonly defined by the term of oxygen storage capacity (OSC). Besides the well known particle size effect, OSC is also strongly dependent on the shape of the ceria particles. Oxygen storage and release can occur both at the surface and in the bulk, in the case of ceria nanorods and nanocubes, but it is restricted only to the surface of nanopolyhedral ceria [27]. Such superior oxygen storage capacity is linked to the fact that the $\{100\}$ - and $\{110\}$-dominated surfaces are inherently more reactive than the $\{111\}$-dominated ones due to the facilitated migration of lattice oxygen from the bulk to the surface. On the other hand, theoretical calculations have predicted that the $\{111\}$ surface has the lowest surface energy whereas the high-energy $\{110\}$ and $\{100\}$ planes are most reactive [28-30]. Experimental studies have confirmed that $\mathrm{CeO}_{2}$ nanorods exposing the $\{100\}$ and $\{110\}$ planes were more catalytically active for $\mathrm{CO}$ oxidation than polyhedral $\mathrm{CeO}_{2}$ nanoparticles enclosed predominantly by the stable $\{111\}$ planes [31,32].

The morphology effect of $\mathrm{CeO}_{2}$ particle is also significant when it is used to support metal particles; the surface property of ceria not only governs the dispersion of the metal particles but also mediates the manner of metal-support interactions [33-37]. For example, a strong shape effect of $\mathrm{CeO}_{2}$ on the activity of $\mathrm{Au} / \mathrm{CeO}_{2}$ catalysts for the water-gas shift (WGS) reaction has been identified [33]. Gold particles dispersed on ceria nanorods that were enclosed by $\{110\}$ and $\{100\}$ planes are the most active system owing to the fact that the rod-shaped ceria can stabilize the tiny Au clusters. Similarly, $\mathrm{CeO}_{2}$ nanorods with a higher concentration of oxygen vacancies not only enhanced the activity of $\mathrm{Pd} / \mathrm{CeO}_{2}$ catalysts for the WGS reaction but also promoted the catalyst's stability by inhibiting the aggregation of Pd nanoparticles under working conditions [34]. The support-dependent activity was also recently demonstrated on $\mathrm{Pt} / \mathrm{CeO}_{2}$ catalysts [36]. Pt clusters dispersed on $\mathrm{CeO}_{2}$ nanorods 


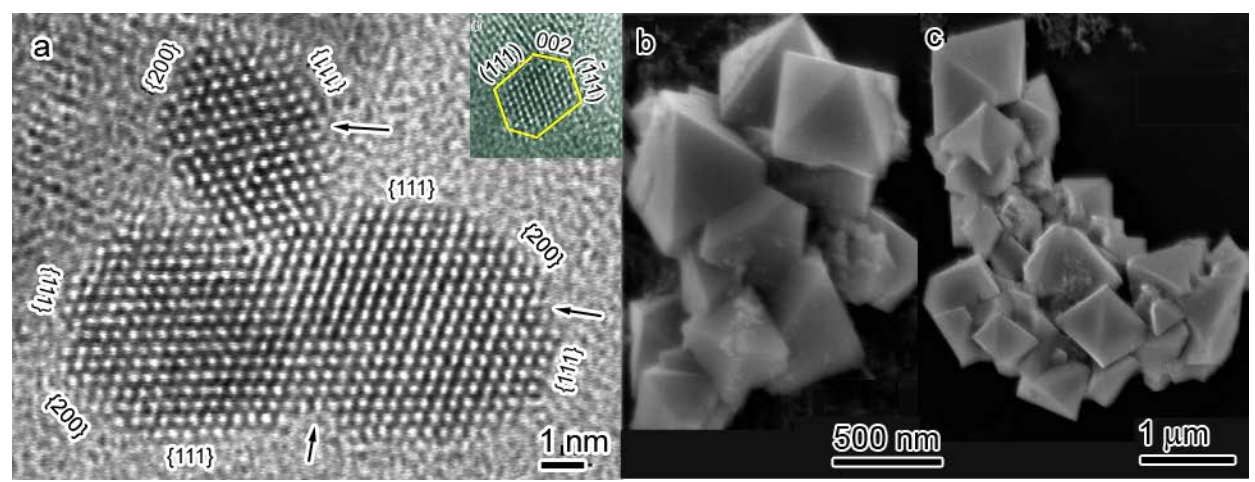

Fig. 1. HRTEM images of small-sized truncated octahedral $\mathrm{CeO}_{2}$ nanoparticles that are enclosed by the $\{100\}$ and (111) facets (a); SEM images of large-sized $\mathrm{CeO}_{2}$ particles, showing an octahedral shape that mainly exposes the $\{111\}$ facets (b, c). Reproduced with permission from Ref. [38]. Copyright 2003 American Chemical Society.

provided a much higher activity in $\mathrm{CO}$ oxidation than those dispersed on $\mathrm{CeO}_{2}$ nanooctahedra; the higher concentration of oxygen vacancies on the surfaces of the ceria nanorods played a significant role in determining its superior activity.

We now believe that the enhanced catalytic properties of ceria nanorods are closely associated with the presence of a large number of oxygen vacancies on the surfaces of the rod-shaped structures. The shape control of ceria particles modulates the nature of the metal-support interactions through the design of specific reactive facets, offering a new strategy to design and fabricate highly efficient ceria-based catalysts. The general approach is to increase the surface fraction of more reactive planes and decrease the fraction of less-reactive planes by precisely tuning the morphology of the catalyst particles. In this review article, we start with a survey of shape-controlled synthesis of ceria nanomaterials using solution-based approaches. Then we examine the catalytic performance of $\mathrm{CeO}_{2}$ and $\mathrm{Au} / \mathrm{CeO}_{2}$ catalysts in the classic probe reactions, CO oxidation and WGS reaction. By analyzing the reaction data and nanoscale structures we elaborate the impact of tuning morphology on the catalytic properties of the interested catalyst systems. Finally, we emphasize the utmost importance of shape control in developing highly efficient ceria-based nanocatalysts.

\section{Shape control of $\mathrm{CeO}_{2}$ nanomaterials}

\subsection{Nanoparticles and nanocubes}

As a typical face-centered cubic structure, ceria nanocrystals are usually enclosed by three low-index surfaces: (111), (110), and (100). Studies on the electronic structure and the chemical coordination patterns of these surfaces provided the relative stability in the order $(111)>(110)>(100)$ [28-30]. Therefore, the most stable (111) planes should dominate the surfaces of a ceria nanoparticle. Accordingly, the energy required to create oxygen vacancies on the (111) surface is greater than those on the (110) and (100) surfaces. In order to minimize the surface energy, ceria particles usually maintain the octahedral or truncated octahedral shape that mainly expose the most thermodynamically stable $\{111\}$ facets. The synthesis of ceria octahedra has been extensively studied for years, and ceria particles with narrow-size distributions in the range of 3-10 $\mathrm{nm}$ can now be easily fabricated in solution phase. The synthetic strategies include aqueous-phase precipitation, hydrothermal synthesis, microemulsion, electrochemical deposition, and thermal decomposition [38-47]. The shape of these ceria particles can be assessed by high-resolution transmission electron microscopy (HRTEM). As shown in Fig. 1, the nanoparticles with a diameter $<10 \mathrm{~nm}$ exhibited a truncated octahedral shape exposing the $\{111\}$ and $\{100\}$ facets while the $\mathrm{CeO}_{2}$ particles with a diameter $>10 \mathrm{~nm}$ possessed an octahedral shape consisting primarily of the $\{111\}$ facets [38].

Encouraged by the theoretical prediction that the polar (100) facet is of highest surface energy and would be catalytically more reactive than either the (111) or the (110) surfaces [30], synthesis of ceria nanocubes has attracted wide attention. The primary synthesis strategy is hydrothermal and/or solvothermal process $[39,43,48-56]$. As illustrated in Fig. 2(a), a facile alkali-assisted hydrothermal process produced $\mathrm{CeO}_{2}$ nanocubes of 20-50 nm [27], and the sizes of the cubes can be further tailored in a wide range of 20 to $360 \mathrm{~nm}$ by simply adjusting the synthetic parameters [49]. However, these cubes are too large to demonstrate appreciable effect in catalytic reactions because the specific surface areas are too small. Use of surfactants or templates under hydrothermal or solvothermal conditions facilitated the attainment of smaller ceria nanocubes (less than $10 \mathrm{~nm}$ ) (Fig. 2(b) and (c)). For example, ceria nanocubes with sizes of 5-10 $\mathrm{nm}$ were prepared by using oleic acid as the structure-directing agent $[39,52,54]$. Recently, single-crystalline ceria nanocubes of about $10 \mathrm{~nm}$ with (100) facets were fabricated using a supercritical hydrothermal process [55]. This cubic nanostructure had surprisingly high extra-low-temperature OSC, demonstrating the potential to be a superior catalyst. However, the strongly adsorbed surfactants on the surfaces of the cubes may block the accessibility to the atoms on the most reactive $\{100\}$ planes, resulting in limitations for practical applications of such catalysts. To date, fabrication of ceria nanocubes with sizes less than $10 \mathrm{~nm}$ still remains a challenge because the high surface energy of the (100) plane forces the particle to grow dominantly along the [100] direction, forming octahedron or truncated octahedron in aqueous phase. But it is reasonable to expect that the $\{100\}$-terminated nanocubes would have exceptionally high 


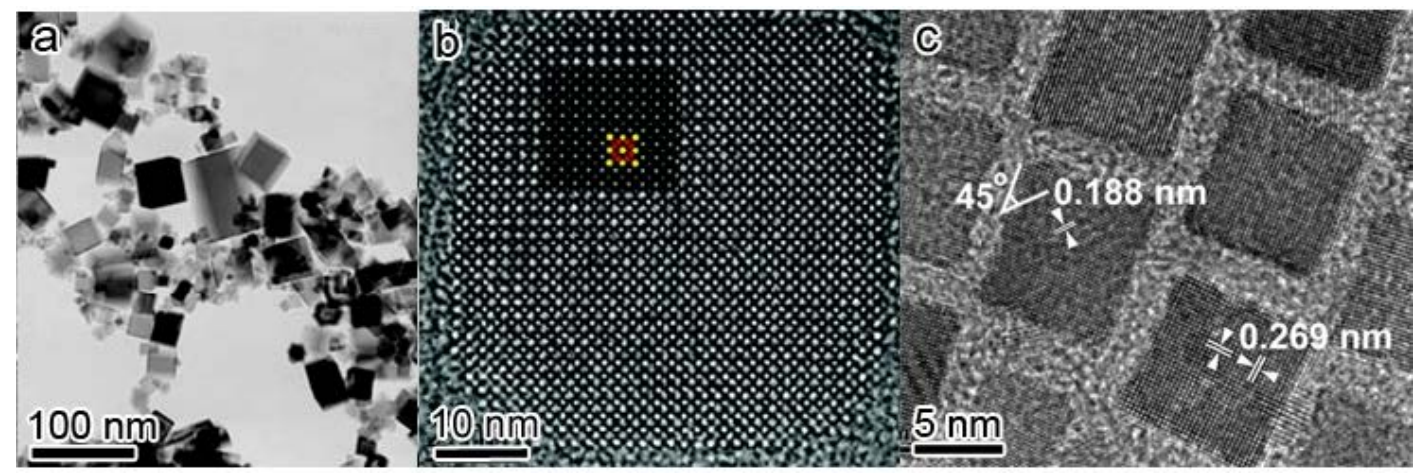

Fig. 2. TEM image of $\mathrm{CeO}_{2}$ cubes with sizes ranging from 20 to $360 \mathrm{~nm}$ (a). Reproduced with permission from Ref. [49]. Copyright 2007 IOP Science. HRTEM image of a single $\mathrm{CeO}_{2}$ nanocube and a simulated image is superimposed onto the experimental image (bright Ce and dark 0) (b). Reproduced with permission from Ref. [48]. Copyright 2007 American Chemical Society. TEM image of ceria nanocubes with the average sizes of 5-10 nm. Reproduced with permission from Ref. [39] (c). Copyright 2006 American Chemical Society.

activity in oxidation reactions provided that smaller cubes can be successfully fabricated and stabilized.

\subsection{Nanorods and nanotubes}

Nanorods and/or nanowires are most desirable in the synthesis of $\mathrm{CeO}_{2}$ materials because of their unique atomic efficiencies with rapid response to changing conditions in the catalytic system $[43,45,57]$. Ceria nanorods preferentially expose the more reactive $\{110\}$ and $\{100\}$ crystalline planes, resulting in a much higher OSC than the conventional spherical nanoparticles which expose mostly stable $\{111\}$ facets. It is generally observed that the reactivity of the $\mathrm{CeO}_{2}$ nanorods increases with the fractions of the $\{100\}$ and $\{110\}$ facets [31,32]. Because of this unique property, the fabrication of $\mathrm{CeO}_{2}$ nanorods or nanowires has been intensively explored and several efficient synthetic routes have been proposed, including hydrothermal or solvothermal synthesis [46,57-61], precipitation [62], sonochemical [63] and electrochemical reduction of cerium salts in liquid phase [64]. So far, the alkali-assisted hydrothermal process seems to be the most effective route [43] Through properly adjusting the alkalinity, the temperature, and the duration, the dimensions of nanorods can be easily tailored. A surfactant- and template-free solution precipitation-hydrothermal approach has been reported to be effective for fabricating $\mathrm{CeO}_{2}$ nanowires with a diameter of about $40 \mathrm{~nm}$ and lengths varying from 3 to $>10 \mu \mathrm{m}$ [61] (Fig. 3(a) and (b)). The recent focus is to further maximize the fraction of the reactive facets [65-67]. $\mathrm{CeO}_{2}$ nanorods with an average diameter of $2.6 \mathrm{~nm}$ and a length of $43 \mathrm{~nm}$ have been synthesized by thermal treatment of a liquid mixture containing cerium acetate, oleic acid, oleyamine, and 1-octadecene [66] (Fig. 3(c)). Most recently, ultra-thin ceria nanorods with extremely small diameters of 1.2-1.5 $\mathrm{nm}$ and lengths of $12-70 \mathrm{~nm}$ were fabricated by a sophisticated sol-gel process and alcoholysis of cerium carboxylate [67], respectively (Fig. 3(d) and (e)).

Synthesis of $\mathrm{CeO}_{2}$ nanotubes is another hot topic with the expectation of high thermal and chemical stabilities together with the inherent high surface area. Theoretical simulation has predicted that ceria nanotubes tend to have a multilayered structure which would create more oxygen vacancies, grain boundaries, and triple junctions on the surface [68]. These defects are potential active sites and thus would promote their catalytic reactivity. Multiple-crystalline $\mathrm{CeO}_{2}$ nanotubes have been routinely fabricated using hard templates such as carbon nanotubes $[69,70]$ and porous alumina [71]. A new route taking advantage of the Kirkendall effect has been used to synthesize $\mathrm{CeO}_{2}$ nanotubes [72]. $\mathrm{CeO}_{2}$ nanotubes less than $100 \mathrm{~nm}$ in diameter having numerous defects in the inner tube and at the tip end have been synthesized by annealing $\mathrm{Ce}(\mathrm{OH})_{3}$ nanotubes which were prepared by hydrothermal treatment of cerium

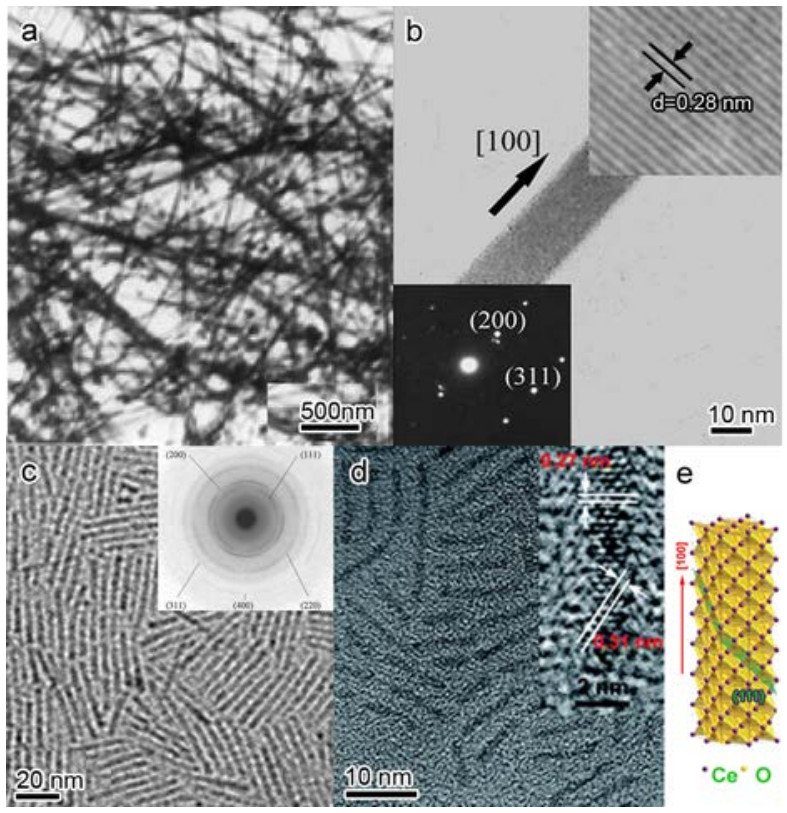

Fig. 3. TEM images of $\mathrm{CeO}_{2}$ nanowires (a), the bottom-left and the upper-right images in micrograph (b) show the selected area electron diffraction (SAED) pattern taken from the same nanowire and the magnified view of the middle part of the nanowire, respectively. Reproduced with permission from Ref. [59]. Copyright 2005 Royal Society of Chemistry. TEM images of $\mathrm{CeO}_{2}$ nanorods having an average diameter of $2.6 \mathrm{~nm}$ and a length of $43 \mathrm{~nm}$ (c). Reproduced with permission from Ref. [66]. Copyright 2010 Elsevier Inc. TEM images of ultra-thin ceria $\mathrm{CeO}_{2}$ nanorods with uniform size (diameters of ca. $1.5 \mathrm{~nm}$ and lengths of about $12 \mathrm{~nm}$ ) and the three-dimensional atomic model of the $\mathrm{CeO}_{2}$ nanorod (d, e). Reproduced with permission from Ref. [67]. Copyright 2010 Royal Society of Chemistry. 


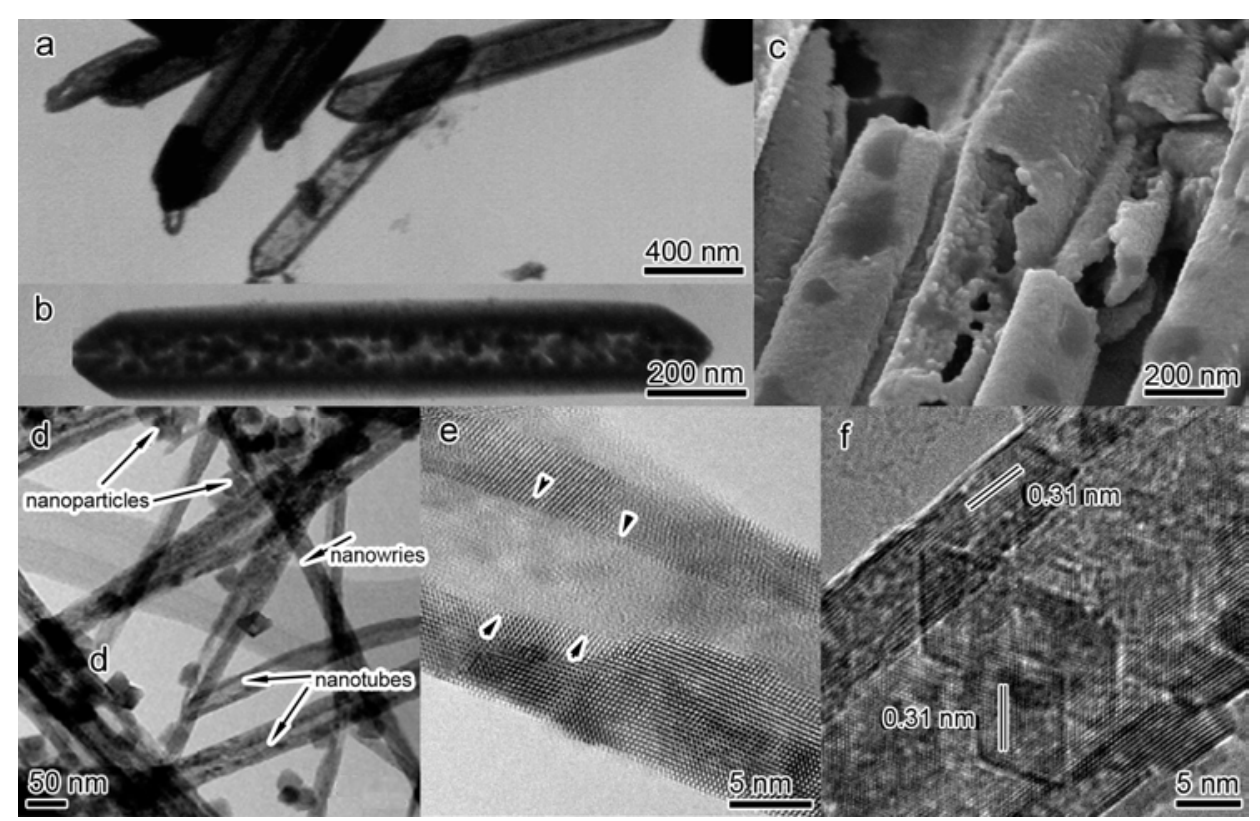

Fig. 4. TEM images of $\mathrm{CeO}_{2}$ nanotubes prepared by taking the advantage of Kirkendall diffusion effect $(\mathrm{a}, \mathrm{b})$. Reproduced with permission from Ref. [72]. Copyright 2009 American Chemical Society. SEM image of $\mathrm{CeO}_{2}$ nanotubes after being extracted from the alumina template (c). Reproduced with permission from Ref. [71]. Copyright 2009 American Chemical Society. TEM images of $\mathrm{CeO}_{2}$ nanotubes with a wall thickness about 5-7 nm (d, e). Reproduced with permission from Ref. [77]. Copyright 2005 American Chemical Society. TEM image for $\mathrm{CeO}_{2}$ nanotubes, showing defects in the inner tube (f). Reproduced with permission from Ref. [75]. Copyright 2007 American Chemical Society.

chloride [73]. However, the diameters of these ceria nanotubes are typically in the range of 200-1000 $\mathrm{nm}$, too large to have appreciable influence on their catalytic properties (Fig. 4(a-c)) [69-74]. On the other hand, synthesis of single-crystalline ceria nanotubes with smaller sizes is still challenging, and most synthetic approaches are either time-consuming or involving complicated procedures with very low yield [75-77]. Ceria nanotubes with a diameter of 5-30 $\mathrm{nm}$ and a wall thickness of 5.5 $\mathrm{nm}$ were fabricated by a time-consuming route including two successive stages: precipitation at $373 \mathrm{~K}$ and aging at $273 \mathrm{~K}$ for 45 days [77] (Fig. 4(d) and (e)). Ceria nanotubes with a wall thickness of 5-7 nm and a inner diameter of 10-15 nm (length up to $100 \mathrm{~nm}$ ) has been prepared by an oxidation-coordination-assisted dissolution process of the hydroxide precursor under ultrasonication [75] as shown in Fig. 4 (f). However, the yield is relatively low and the final product is often a mixture of tubes, particles, and rods. Therefore, efficient preparation of $\mathrm{CeO}_{2}$ nanotubes with desired crystallinity and smaller diameters remains a grand challenge.

\subsection{Multi-dimensional nanostructures}

The fabrication of multi-dimensional $\mathrm{CeO}_{2}$ nanostructures has not been intensively investigated so far [78]. As illustrated in Fig. 5, an interesting work has revealed that very thin $\mathrm{CeO}_{2}$ nanoplates (thickness of $3 \mathrm{~nm}$ and average diameter of $40 \mathrm{~nm}$ ) preferentially exposing the $\{100\}$ facets were found to be more active for CO oxidation than the nanotubes (diameter of $25 \mathrm{~nm}$ and length of $200 \mathrm{~nm}$ ) and nanorods (20 nm in diameter and $500 \mathrm{~nm}$ in length) which mainly expose the $\{110\}$ facets [79]. Subnanometer-thick nanoplates (thickness of less than $1 \mathrm{~nm}$ and linear size of 20-80 $\mathrm{nm}$ ) were prepared by a slow hydroly- sis of cerium nitrate in aqueous solution using hexamethylenetetramine as the structure-directing agent [80]. Recently, $\mathrm{CeO}_{2}$ nanoplates having a thickness of about $2 \mathrm{~nm}$ have been pre-

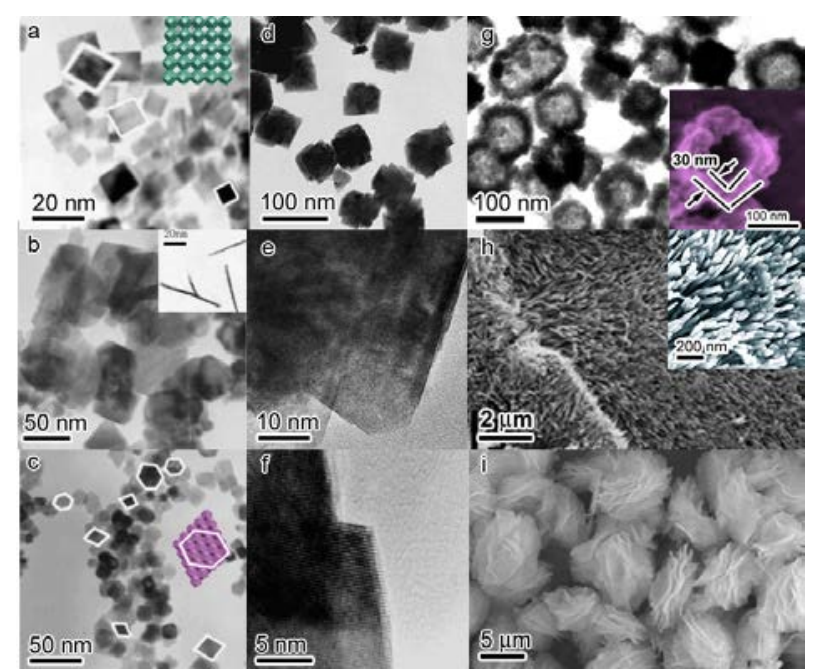

Fig. 5. Multi-dimensional $\mathrm{CeO}_{2}$ nanostructures. (a-c) TEM images of the $\mathrm{CeO}_{2}$ nanoplates with the thickness of $3 \mathrm{~nm}$ and the average size of 40 $\mathrm{nm}$ that preferentially exposed the reactive $\{100\}$ facets. Reproduced with permission from Ref. [79]. Copyright 2008 Elsevier Inc. (d-f) Subnanometer-thick $\mathrm{CeO}_{2}$ nanoplates (thickness of less than $1 \mathrm{~nm}$ and linear size of 20-80 nm). Reproduced with permission from Ref. [80]. Copyright 2009 Springer. (g) Single-crystalline-like $\mathrm{CeO}_{2}$ hollow nanocubes with an average edge length of $120 \mathrm{~nm}$ and a shell thickness of $30 \mathrm{~nm}$. Reproduced with permission from Ref. [89]. Copyright 2008 American Chemical Society. (h) SEM images of well-aligned $\mathrm{CeO}_{2}$ nanorods arrays. Reproduced with permission from Ref. [82]. Copyright 2008 American Chemical Society. (i) SEM image of the 3D flowerlike ceria. Reproduced with permission from Ref. [83]. Copyright 2007 American Chemical Society. 
pared by a facile and robust solution phase approach with the assistance of mineralizers that accelerate the crystallization process and control the morphology of ceria nanocrystals [81]. The obtained ceria nanoplates that are enclosed by six (100) facets exhibited a much higher oxygen storage capacity. Hierarchical structures such as arrays of nanorods [82], flowery shapes [83,84], nanopindles [85], and hollow spheres [86-88] were synthesized by hydrothermal-like processes with the aid of complicated structure-directing agents. Most interestingly, single-crystalline-like $\mathrm{CeO}_{2}$ hollow nanocubes with an average edge length of $120 \mathrm{~nm}$ and a shell thickness of $30 \mathrm{~nm}$ have been fabricated solvothermally using peroxyacetic acid as the oxidant without using any template [89]. This hollow structure was well retained at relatively high temperatures (up to $573 \mathrm{~K}$ ) and exhibited a higher catalytic activity toward CO oxidation.

\section{Gold-ceria interfacial structure in $\mathrm{Au} / \mathrm{CeO}_{2}$ catalysts}

Because the exciting finding that nanosized gold particles, dispersed on metal oxides, were highly active for low-temperature oxidation of CO [5], intense studies have continuously addressed the nature of the active sites [8,9,90-92]. A general consensus is that the origin of the catalytic activities of gold can be assigned to the interfacial perimeters between $\mathrm{Au}$ nanoparticles and their oxide supports. In addition to the size effect of gold particles ( $<5 \mathrm{~nm}$ to achieve high activity), oxide supports also affect their catalytic performance significantly, and reducible oxides with highly mobile lattice oxygen are typically superior to non-reducible ones [9,93-95]. Among these systems, $\mathrm{Au} / \mathrm{CeO}_{2}$ catalysts have gained particular attention because of their exceptionally high activities in low-temperature CO oxidation and WGS reaction. These two probe reactions typically occur on the gold-ceria interface where the gold particle provides adsorption sites for $\mathrm{CO}$ and the ceria support supplies oxygen species generated either from molecular oxygen or water in the feed stream. In such a reaction model, the $\mathrm{CeO}_{2}$ support plays two essential roles. One is to offer active oxygen species through a redox cycle between the lattice oxygen and the molecular oxygen or water in gas phase $[96,97]$ and the other is to disperse and stabilize gold species through strong metal-support interactions [98]. Both functions require the participation of the surface oxygen vacancies which are intimately associated with the size and shape of the $\mathrm{CeO}_{2}$ particles. Two prominent works on $\mathrm{Au} / \mathrm{CeO}_{2}$ catalysts provided convincing experimental data and facilitated such a fundamental understanding $[33,99]$. $\mathrm{CeO}_{2}$ nanocrystallites of about $3 \mathrm{~nm}$ increased the activity of gold nanoparticles for $\mathrm{CO}$ oxidation by two orders of magnitude owing to the large amounts of surface oxygen vacancies on ceria [99]. $\mathrm{CeO}_{2}$ nanorods enhanced the activities of gold particles for low-temperature WGS reaction because of the strong gold-ceria interaction, induced by the dominantly exposed reactive $\{110\}$ and $\{100\}$ planes that greatly facilitated the generation of oxygen vacancies [33] (Fig. 6).

Based on the general understanding that the shape of ceria particles has considerable influence on the active gold-ceria interfacial perimeters, $\mathrm{CeO}_{2}$ nanorods, nanocubes, and nano-

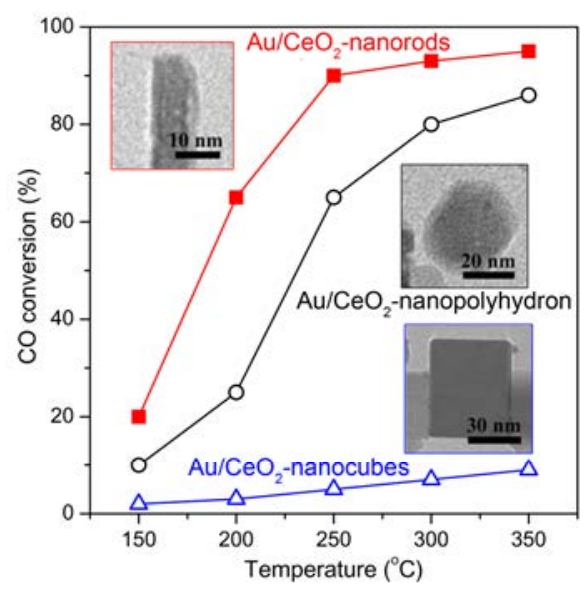

Fig. 6. $\mathrm{Au}$ nanoparticles supported on $\mathrm{CeO}_{2}$ nanorods, nanoparticles, and nanocubes and their activities in the water-gas shift reaction. Reproduced with permission from Ref. [33]. Copyright 2008 Wiley-VCH Verlag GmbH \& Co. KGaA.

particles have been used to disperse gold nanoparticles, and the impact of their morphology has been examined in catalytic reactions. $\mathrm{CeO}_{2}$ nanorods with diameters of 20-30 nm and lengths up to tens of micrometers were used to support $\mathrm{Au}$ nanoparticles with crystallite sizes of 10-20 nm, but the activity for CO oxidation was not impressive perhaps due to the large sizes of the two components [100]. Gold clusters supported on ceria nanoparticles, nanorods, and nanocubes were comparatively examined for CO oxidation [101,102] and preferential oxidation of CO in rich hydrogen $[103,104]$. The shapes of ceria particles significantly affected the dispersion of gold nanoparticles and subsequently the $\mathrm{Au}-\mathrm{CeO}_{2}$ interactions. Most of the $\mathrm{Au}$ species on $\mathrm{CeO}_{2}$ nanorods $(10 \mathrm{~nm}$ in diameter and $50-200 \mathrm{~nm}$ in length) were found to be in the form of $\mathrm{Au}^{+}$and/or $\mathrm{Au}^{3+}$, which differed largely from those on $\mathrm{CeO}_{2}$ nanocubes $(26 \mathrm{~nm})$ or nanoparticles $(8 \mathrm{~nm})$, resulting in a much higher activity. $\mathrm{Au}$ nanoparticles dispersed on ceria nanorods, nanocubes, and nanopolyhedra were also investigated for WGS reaction $[33,105] . \mathrm{CeO}_{2}$ nanorods, enclosed by $\{110\}$ and $\{100\}$ planes, bonded gold particles more strongly and created more active sites, resulting in a considerably enhanced activity. When used to catalyze methanol steam reforming, subnanometer gold clusters on rod-like $\mathrm{CeO}_{2}$ still exhibited a much better reactivity than those on $\mathrm{CeO}_{2}$ nanocubes $[35,106,107]$. These results consistently affirmed that gold nanoparticles on ceria nanorods are more active than those on $\mathrm{CeO}_{2}$ nanoparticles or nanocubes; the rod-like structures efficiently stabilize $\mathrm{Au}$ particles and/or cationic species through the presence of large amounts of surface oxygen vacancies.

The gold-ceria interactions simultaneously involve the surface oxygen vacancies of ceria and the specific chemical states of gold species [108]. The function of the oxygen vacancies is to stabilize metal particles against sintering through strong chemical bonding [109]. The chemical nature of the surface oxygen vacancies on $\mathrm{CeO}_{2}\{111\}$ have been indentified to be linear clusters that exclusively expose $\mathrm{Ce}^{3+}$ ions [110], and these types of cluster vacancies have promoted the reducibility 
of ceria nanorods that predominantly expose the $\{100\}$ and $\{110\}$ planes [111]. On the other hand, Au particles, clusters, and cationic species with a rather wide size distribution are often present in most of the $\mathrm{Au} / \mathrm{CeO}_{2}$ catalysts; their contributions to the overall reaction efficiency are, however, controversial $[35,97,112]$. Faceted gold particles on ceria can be easily identified by HRTEM technique, but the tiny clusters (less than $1 \mathrm{~nm}$ ) as well as the cationic species are mostly invisible and can hardly be observed in HRTEM images, hindering a conclusive understanding of the shape effect of Au particles. To date, the intrinsic nature of the gold-ceria interfacial structures is still highly speculative although we are convinced that the morphology of $\mathrm{CeO}_{2}$ affects its catalytic performance significantly.

It is well acknowledged that the gold-ceria interface acts as the active site in CO oxidation $[9,90,99,113]$, in which the OSC of ceria and the sizes of gold particles are the key parameters. The former is responsible for the activation of oxygen molecules, while the later adsorbs and activates CO. However, very little is known with respect to the dynamic behavior of the gold-ceria interfaces under the reaction conditions. $\mathrm{Au} / \mathrm{CeO}_{2}$ catalysts with well-defined sizes and shapes can be synthesized, but such nanostructures vary largely during the course of reaction because both the temperature and the gas constituents induce changes in surface and interface energies. Consequently, unless strongly anchored, Au nanoparticles sinter rapidly under realistic reaction conditions, the gold-ceria interfacial regions would be dramatically modified.

In fact, direct observation of working solid catalysts and their structural evolution during the course of reaction is of utmost importance in obtaining insights into the relationship between the catalyst nanostructure and the reaction performance [114]. The variations in size and shape of gold particles at elevated temperatures in the $\mathrm{Au} / \mathrm{CeO}_{2}$ catalysts have been observed [115-119]. One interesting phenomenon was that the
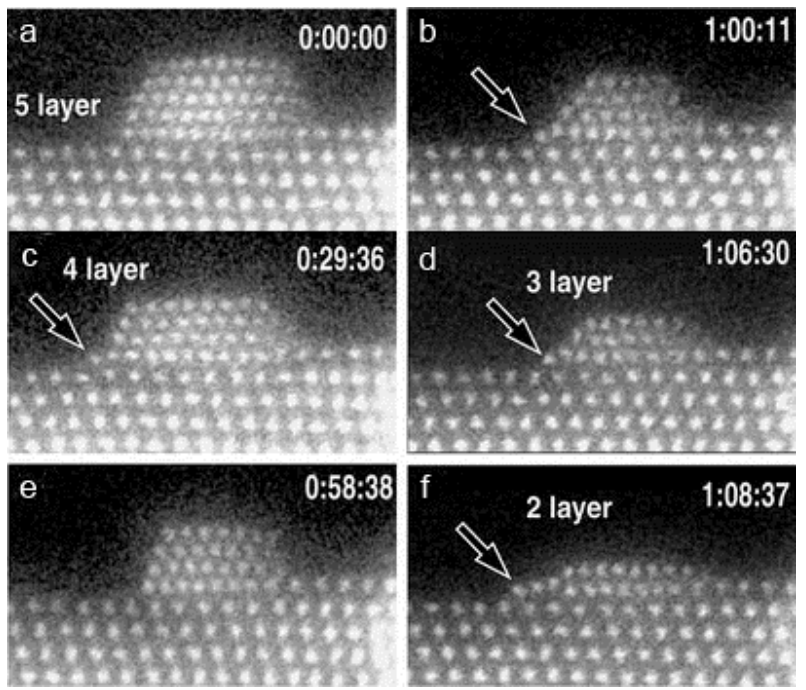

Fig. 7. Sequential high-angle annular dark-field scanning transmission electron microscopy (HADDF-STEM) images of the structural change of an $\mathrm{Au}$ nanoparticle on $\mathrm{CeO}_{2}$ under electron beam irradiation. Reproduced with permission from Ref. [119]. Copyright 2011 Springer. atomic structure at the perimeters of the $\mathrm{Au} / \mathrm{CeO}_{2}$ interfaces changed significantly through a cyclic process of layer-by-layer shrinkage and recovery of Au nanoparticles (Fig. 7). During the TEM observations, relatively small $\mathrm{Au}$ nanoparticles were found to shrink layer-by-layer and eventually disappear, whereas a monolayer tended to remain. After the electron beam was turned off and the sample remained in the chamber, $\mathrm{Au}$ nanoparticles were found to recover at the same positions. This dynamic behavior is likely associated with the formation and annihilation of oxygen vacancies in $\mathrm{CeO}_{2}$. The $\mathrm{Au}$ atoms at the edges of the interfacial perimeters bonded to oxygen vacancies or Ce-terminated surface regions. These visual results provided valuable insights into the mechanisms of structural changes of the $\mathrm{Au} / \mathrm{CeO}_{2}$ catalysts. However, since the observations were conducted inside the vacuum chamber of the electron microscope, there is no guarantee that the observed phenomenon represents the true behavior of $\mathrm{Au}$ particles under reaction atmospheres. Most recently, the shape changes of $\mathrm{Au}$ nanoparticles in $\mathrm{Au} / \mathrm{CeO}_{2}$ catalysts have been examined under reactive gases at ambient temperature. It was interestingly observed that $\mathrm{CO}$ adsorbed at the on-top sites of $\mathrm{Au}$ atoms on the nanoparticles caused the particle to restructure during CO oxidation at room temperature [120]. In particular, the reconstruction mainly occurred on the $\{100\}$ facets of the Au nanoparticle; the surface structure of the $\{100\}$ facets underwent modifications that allowed $\mathrm{CO}$ adsorption at a higher surface converages. This morphology change in Au nanoparticles corrected well with the catalytic activity in CO oxidation [121]. CO molecules were adsorbed on the surface of $\mathrm{Au}$ nanoparticles and simultaneously stabilized the $\mathrm{Au}$ particle in polyhedral shape enclosed by the major $\{111\}$ and $\{100\}$ facets; $\mathrm{O}_{2}$ molecules were dissociated into active oxygen species probably at the perimeter interface between Au nanoparticles and the ceria support, inducing the formation of rounded or fluctuating multifaceted surfaces of Au nanoparticles. These atomic-scale visualizing evidences deepened the mechanistic understanding of gold-ceria catalysts under reactive atmospheres at ambient temperature (Fig. 8).

We have prepared $\mathrm{CeO}_{2}$ nanorods and nanoparticles and examined their shape effects in $\mathrm{Au} / \mathrm{CeO}_{2}$ catalysts [32,113]. The $\mathrm{CeO}_{2}$ nanorods were prepared by an alkali-assisted hydrothermal process, while the nanoparticles were prepared by a conventional aqueous-phase precipitation route. As generally expected, the spherical nanoparticles mainly exposed the most thermodynamically stable $\{111\}$ facets, whereas the nanorods were dominantly enclosed by the reactive $\{110\}$ and [100] planes [32]. This result reaffirms that the morphology-dependent effect of ceria nanostructures and the higher OSC of the nanorods are largely responsible for the enhanced CO oxidation activity. In order to maintain their stable shapes during the assembly of $\mathrm{Au} / \mathrm{CeO}_{2}$ catalysts, both nanoparticles and nanorods were calcined at $973 \mathrm{~K}$ in air. Consequently, the $\mathrm{CeO}_{2}$ nanoparticles had an average size of $12 \mathrm{~nm}$ with predominantly exposing the $\{111\}$ facets. The nanorods had an average diameter of about $8 \mathrm{~nm}$ and lengths ranging from 80 to $150 \mathrm{~nm}$, mainly enclosed by the $\{111\}$ planes (Fig. 9).

$\mathrm{Au}$ nanoparticles were loaded on these ceria nanostructures 


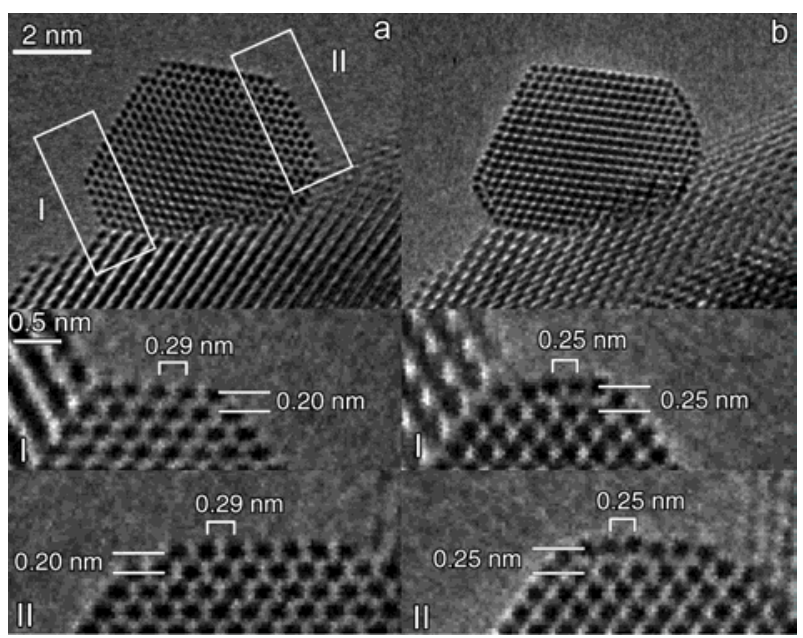

Fig. 8. $\mathrm{Au}\{100\}$-hex reconstructed surface under catalytic conditions. $\mathrm{Au}$ nanoparticles supported on $\mathrm{CeO}_{2}$ in a vacuum (a) and a reaction environment ( $1 \mathrm{vol} \% \mathrm{CO}$ in air gas mixture at $45 \mathrm{~Pa}$ at room temperature) (b). Two $\{100\}$ facets are present in the rectangular regions indicated by I and II in (a). The enlarged images of these regions in vacuum and in the $\mathrm{CO}$ in air gas mixture are shown at the bottom of (a) and (b), respectively. Reproduced with permission from Ref. [121]. Copyright 2012 American Association for the Advancement of Science.

by a deposition-precipitation method, followed by calcination of the samples at $673 \mathrm{~K}$ in order to assure that the chemical state of the Au particles was metallic. The average size of the Au particles on the nanorods was about $3 \mathrm{~nm}$ whereas it was $4 \mathrm{~nm}$ on the nanoparticles, showing the advantage of the rod-shaped support in dispersing gold particles. It is noteworthy that $\mathrm{Au}$ particles on the $\mathrm{CeO}_{2}$ nanorods had a polyhedral shape but they maintained a hemispherical shape on the $\mathrm{CeO}_{2}$ nanoparticles, reflecting substantially different types of interfacial structures between the $\mathrm{Au}$ particles and the ceria supports (Fig. 10). In other words, the $\mathrm{Au}-\mathrm{CeO}_{2}$ interface had an acute angle on the nanorods but rather an obtuse angle on the nanoparticles. The smaller contact angle between gold and ceria suggested a higher interfacial energy and thus a much stronger $\mathrm{Au}-\mathrm{CeO}_{2}$ inter- action on the nanorods-shaped support. That is, the bonding of gold particles on ceria nanorods was much stronger than that on the nanoparticles.

The $\mathrm{Au} / \mathrm{CeO}_{2}$-nanorods catalyst was highly active and exceptionally stable for $\mathrm{CO}$ oxidation at room temperature and the conversion of CO maintained at the level of $75 \%-90 \%$ for $40 \mathrm{~h}$ on-stream. On the $\mathrm{Au} / \mathrm{CeO}_{2}$-nanoparticles catalyst, however, the conversion of CO was only $70 \%$ at the initial stage, followed by a rapid deactivation with the $\mathrm{CO}$ conversion of only about $30 \%$ at the end of the operation. Supported Au nanoparticles often showed distinctively high initial activity but suffered from a rapid deactivation caused by the easy sintering of $\mathrm{Au}$ nanoparticles. Here, the outstanding stability achieved on the $\mathrm{Au} / \mathrm{CeO}_{2}$-nanorods catalyst is straightforwardly attributed to the strong chemical bonding of gold onto $\mathrm{CeO}_{2}$ nanorods. Kinetic studies further revealed that for $\mathrm{CO}$ oxidation the turnover frequency of the $\mathrm{Au} / \mathrm{CeO}_{2}$-nanorods catalyst was much higher than that of the $\mathrm{Au} / \mathrm{CeO}_{2}$-nanoparticles catalyst. By adjusting the sizes of Au particles on both catalysts to about 4-7 $\mathrm{nm}$, the turnover frequencies of gold in $\mathrm{CO}$ oxidation at room temperature were $1.8 \times 10^{-2} \mathrm{~s}^{-1}$ on $\mathrm{CeO}_{2}$ nanoparticles and $2.7 \times 10^{-2} \mathrm{~s}^{-1}$ over $\mathrm{CeO}_{2}$ nanorods (CO conversion was $3 \%-5 \%$ ). These experimental data clearly showed that ceria nanorods not only enhanced the activity but also stabilized the Au particles during $\mathrm{CO}$ oxidation.

We further used environmental TEM (ETEM) to directly observe the evolutions of the gold-ceria interfaces in the $\mathrm{Au} / \mathrm{CeO}_{2}$-nanorods catalyst under oxidizing and reducing atmospheres at $573 \mathrm{~K}$ [122] (Fig. 11). In an oxidizing environment ( $10 \mathrm{vol} \% \mathrm{O}_{2} / \mathrm{N}_{2}$ ), the Au particles of about $3 \mathrm{~nm}$ in diameter rotated and vibrated locally but did not move to aggregate. They were tightly anchored on ceria nanorods and the gold-ceria interfacial structure remained stable. When exposed to a relatively reducing but reactive atmosphere (42 vol\%CO-6 vol $\% \mathrm{O}_{2} / \mathrm{N}_{2}$ ), the gold-ceria interfaces gradually restructured with the emerging of $\mathrm{CeO}_{2}$ layer around the gold particle. With extending the reaction time, more ceria layers appeared around the $\mathrm{Au}$ particle and the gold-ceria interfaces dynami-
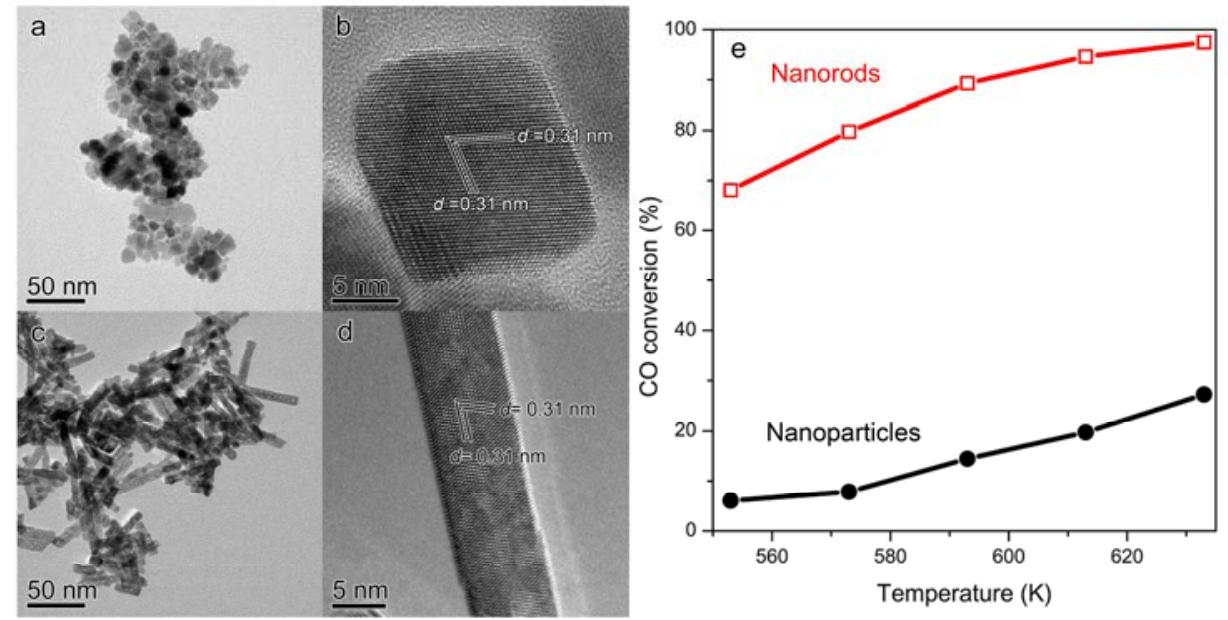

Fig. 9. TEM images of the $\mathrm{CeO}_{2}$ nanoparticles with an average size of $12 \mathrm{~nm}(\mathrm{a}, \mathrm{b})$. TEM images of the $\mathrm{CeO}_{2}$ nanorods having an average diameter of about $8 \mathrm{~nm}$ and lengths of $80-150 \mathrm{~nm}(\mathrm{c}, \mathrm{d})$. $\mathrm{CO}$ oxidation activities of the $\mathrm{CeO}_{2}$ nanoparticles and nanorods (e). The reaction was conducted with a 1.0 vol\%CO-20.0 vol\% $\mathrm{O}_{2} / \mathrm{N}_{2}(30000 \mathrm{ml} /(\mathrm{g} \cdot \mathrm{h}))$. 


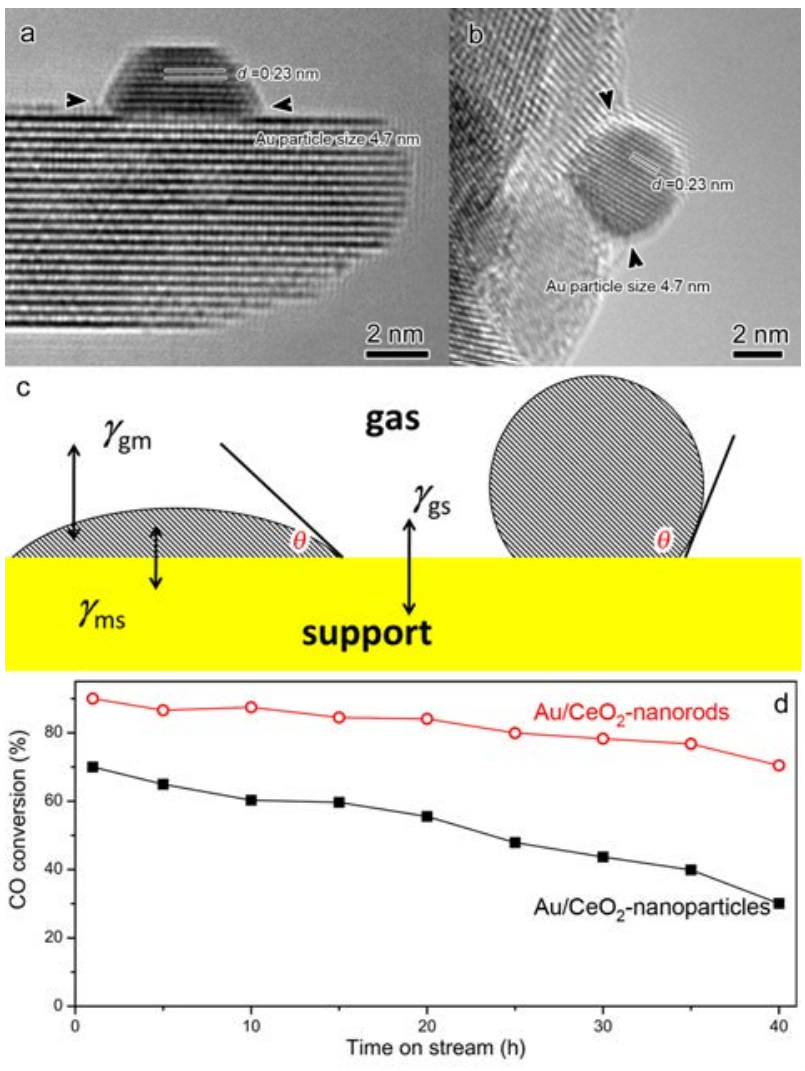

Fig. 10. HRTEM images and contact patterns of a gold nanoparticle on $\mathrm{CeO}_{2}$ nanorods and nanoparticles (a-c). $\mathrm{CO}$ oxidation at room temperature in $1.0 \mathrm{vol} \% \mathrm{CO}-1.0 \mathrm{vol} \% \mathrm{O}_{2} / \mathrm{N}_{2}, 30000 \mathrm{ml} /(\mathrm{g} \cdot \mathrm{h})(\mathrm{d})$.

cally fluctuated. At the same time, the shape of the Au particles changed, primarily driven by the underlying redox cycle of the ceria support involving the participation of oxygen vacancies. Under this reactive atmosphere, $\mathrm{CO}$ adsorbed on the Au particle and reacted with nearby ceria lattice oxygen, forming $\mathrm{CO}_{2}$ and simultaneously generating more oxygen vacancies. The subsequent oxidation by gas phase oxygen molecules restored the stoichiometric $\mathrm{CeO}_{2}$ composition. This redox cycle reshaped the $\mathrm{Au}$ particles and accordingly reconstructed the gold-ceria interfaces. These observations have convincingly demonstrated that the $\mathrm{CeO}_{2}$ nanorods not only control the equilibrium shape of the $\mathrm{Au}$ particles via the presence of large amount of surface oxygen vacancies, forming a stable $\mathrm{Au}-\mathrm{CeO}_{2}$ interfacial structure that offered rather high activity for $\mathrm{CO}$ oxidation, but also stabilize the $\mathrm{Au}$ particles even at temperature up to $573 \mathrm{~K}$. The dynamic behavior of the gold-ceria interface structure will have a strong impact on the design and fabrication of active and stable $\mathrm{Au}$ nanocatalysts through morphology control of the ceria support.

\section{Conclusions and perspectives}

Nanomaterials that preferentially expose the reactive facets through size and shape control provide the possibility to finely tune the catalytically active sites. The ultimate goal of shape-dependent nanocatalysis is to design and fabricate catalytic materials that could expose more active sites within a uniform nanostructure. The approach of integrating nanomaterials fabrication and surface science offers a new strategy to study the fundamental question of intrinsic structure-reactivity relationship and to create highly efficient heterogeneous catalysts for practical applications. As a widely used metal oxide, ceria showed an apparent shape-dependent phenomenon with the general observation that the nanorods-shaped structure with primarily exposing the $\{110\}$ and $\{100\}$ facets is more active in oxidation reactions than the conventional spherical nanoparticles. Such a unique behavior is correlated with the high surface energies of the $\{110\}$ and $\{100\}$ facets. Moreover, the shape of ceria particles also alters the gold-ceria interfacial perimeters and consequently affects the catalytic activities of $\mathrm{Au} / \mathrm{CeO}_{2}$ catalysts for low-temperature $\mathrm{CO}$ oxidation and water-gas shift reactions. The morphological effect can now be experimentally investigated by dispersing gold nanoparticles on ceria nanostructures and theoretically studied on the basis of surface science findings on single nanocrystals and density-functional theory calculations [98,108,123-128].

In this context, skillful synthesis of shape-controlled ceria-based nanomaterials will be the most priority. The major topics might be: (1) high percentage of exposure of (100) and/or (110) planes on ceria nanostructures, like nanorods, nanocubes, and nanotubes with smaller dimensions, (2) the contributions of different planes to the total reaction and the synergetic function among the crystalline planes, and (3) ceria-based binary oxide nanocrystals, in particular $\mathrm{CeO}_{2}-\mathrm{ZrO}_{2}$ [129-131], $\mathrm{CeO}_{2}-\mathrm{MnO}_{2}$ [132,133], and $\mathrm{CeO}_{2}-\mathrm{TiO}_{2}$ [134-136]. These mixed oxides, often in the form of solid solutions, are more efficient as catalytic materials than ceria alone. Because of the different nucleation behavior and growth kinetics of cerium and zirconium (manganese or titanium) species in solution phase, however, effective control of the mixed oxides with respect to homogeneous chemical composition, uniform crystallinity, and tunable shape is challenging. In addition, the stability of the oxide particles under catalytic reaction conditions is another ground challenge. Up to date, most of the ceria-related nanoparticles, especially nanorods, nanowires, and nanocubes, have been prepared in liquid phase and their sizes and shapes were maintained only in the presence of complicated capping agents. When used for catalytic reactions, however, the surface atomic configurations might experience rearrangement or reconstruction induced by the temperature and the reaction atmosphere. Meanwhile, the role of the surfactant used to maintain the specific nanostructures is somewhat controversial in interpreting the catalytic properties. In most cases, significant amounts of surfactants have been used to direct the fabrication of the nanostructures. The size and shape was readily controlled by mediating the relative growth rate of different crystal planes, realizing a preferential exposure of the desired reactive facets. But this approach only results in a kinetically stable nanostructure. The exposed facets may easily transform into thermodynamically stable spherical nanoparticles upon exposure to the reaction conditions or removing the surfactants. Therefore, more efficient routes to prepare ceria nanomaterials with stable size and shape, hopefully without the presence of 


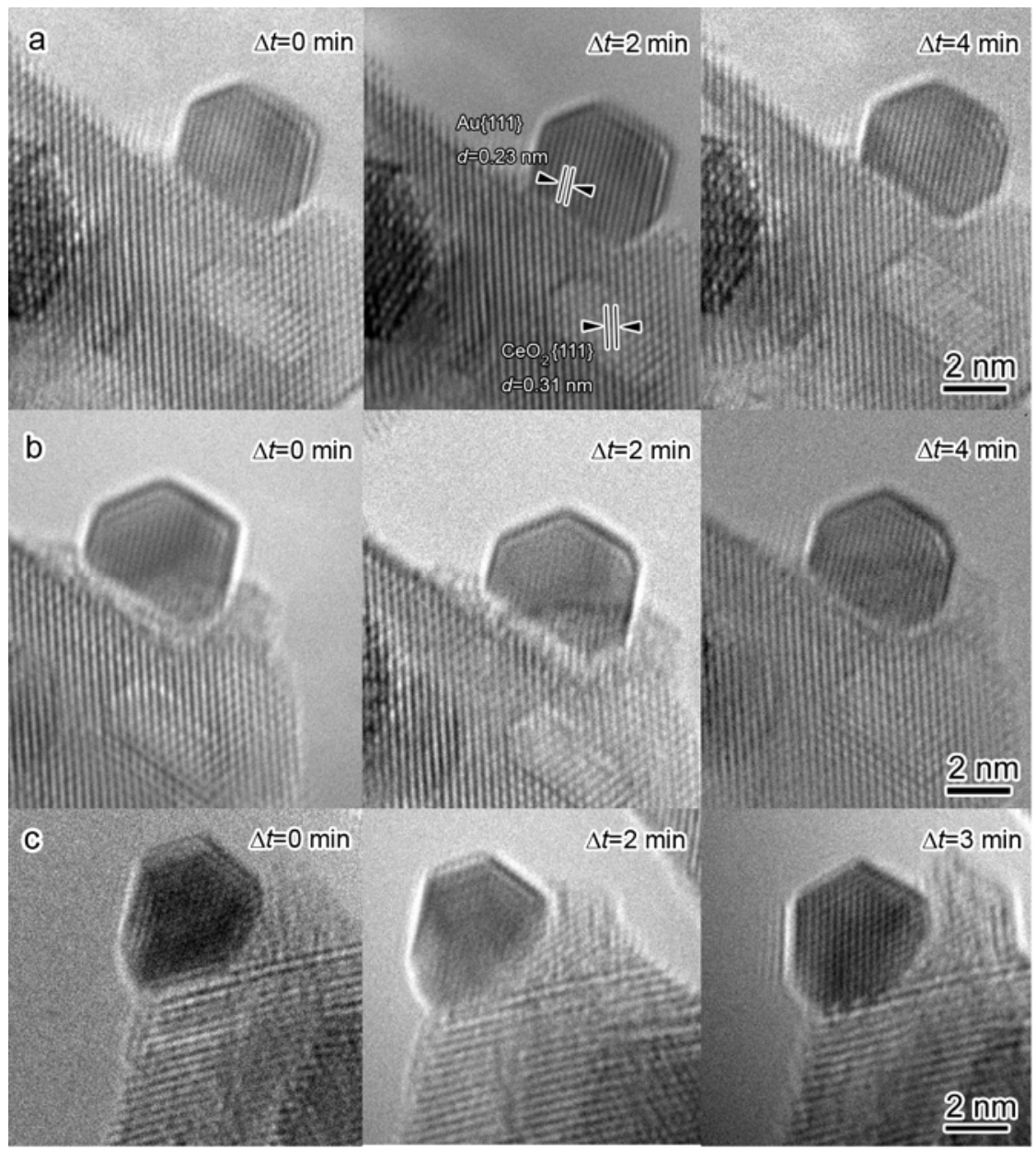

Fig. 11. ETEM images of the $\mathrm{Au} / \mathrm{CeO}_{2}$-nanorods catalyst under oxidizing and reducing atmospheres at $573 \mathrm{~K}$. A stable truncated octahedral Au particle (ca. $3 \mathrm{~nm}$ ) under $10 \mathrm{vol} \% \mathrm{O}_{2} / \mathrm{N}_{2}$ atmosphere (a) and under $42 \mathrm{vol} \% \mathrm{CO}-6 \mathrm{vol} \% \mathrm{O}_{2} / \mathrm{N}_{2}$ environment (b), respectively. Another Au particle of about 3 $\mathrm{nm}$ in size under a $42 \mathrm{vol} \% \mathrm{CO}-6 \mathrm{vol} \% \mathrm{O}_{2} / \mathrm{N}_{2}$ atmosphere at $573 \mathrm{~K}$, clearly showing that reshaping of the gold particle was associated with the increase in the thickness of the growing ceria layers at the gold-ceria interfacial region and the chemical nature of the newly formed ceria layers was identified as $\mathrm{CeO}_{1.714}$ (c). Reproduced with permission from Ref. [122]. Copyright 2012 American Chemical Society.

surfactants or to remove the surfactants easily while maintaining the nanostructure, are highly expected.

Concerning the $\mathrm{Au} / \mathrm{CeO}_{2}$ catalysts, in spite of a huge number of studies on this topic, the nature of the active sites is still under debate. The challenges are: (1) quantitative determination of the size and shape of gold particles on ceria, especially the subnanometer gold clusters and the possible cationic gold species; (2) size and shape control of gold particles/clusters on the (111), (110), and (100) facets of ceria; (3) selective anchoring of gold particles on a specific surface plane of ceria and quantitative control of gold-ceria interfacial structures; and (4) dynamic behavior of the gold-ceria interfaces under realistic reaction conditions. The catalytic stability has long been viewed as a pivotal challenge for gold nanocatalysts. In most cases, $\mathrm{Au} / \mathrm{CeO}_{2}$ catalysts showed exceptionally high activities at the initial stages of the chemical reactions, but followed by rapid deactivations. This is inherently associated with the easy sintering of $\mathrm{Au}$ nanoparticles under reactive atmospheres and at elevated temperatures, which restructures the gold-ceria interfaces. Direct observation of the $\mathrm{Au} / \mathrm{CeO}_{2}$ catalysts at functionalizing states, for example CO oxidation and water-gas shift reaction, may reveal fundamental mechanisms of the gold-ceria interfacial reactions and thus provide clues to solve the deactivation problem by enhancing the chemical bonding of gold on ceria. ETEM has now opened up the unique possibility to monitor the structural evolution of heterogeneous catalysts during exposure to reactive gases at elevated temperatures, allowing us to directly image the size, shape, and interfacial structures of individual nanoparticles in their working state and identify the dynamic structures of gas-induced changes at the interfacial regions. Together with the conventional spectroscopic techniques used for the study of working catalysts, the dynamic behavior of supported metal catalysts including the $\mathrm{Au} / \mathrm{CeO}_{2}$ system would be well explored and the intrinsic active structures under catalytic conditions would be clarified convincingly.

\section{References}

[1] Bell A T. Science, 2003, 299: 1688

[2] Somorjai G A, Li Y M. Top Catal, 2010, 53: 311

[3] Murzin D Y.J Mol Catal A, 2010, 315: 226

[4] Valden M, Lai X, Goodman D W. Science, 1998, 281: 1647 
[5] Haruta M, Kobayashi T, Sano H, Yamada N. Chem Lett, 1987: 405

[6] Haruta M, Yamada N, Kobayashi T, Iijima S. J Catal, 1989, 115: 301

[7] Haruta M. CATTECH, 2002, 6(3): 102

[8] Haruta M. Nature, 2005, 437: 1098

[9] Haruta M. Faraday Discuss, 2011, 152: 11

[10] Ertl G. Angew Chem, Int Ed, 2008, 47: 3524

[11] Zaera F. Acc Chem Res, 2009, 42: 1152

[12] van Santen R A, Neurock M, Shetty S G. Chem Rev, 2010, 110: 2005

[13] Narayanan R, El-Sayed M A. Nano Lett, 2004, 4: 1343

[14] Narayanan R, El-Sayed M A. J Am Chem Soc, 2004, 126: 7194

[15] Narayanan R, El-Sayed M A.J Phys Chem B, 2005, 109: 12663

[16] Tian N, Zhou Zh Y, Sun Sh G, Ding Y, Wang Zh L. Science, 2007, 316:732

[17] Bratlie K M, Kliewer C J, Somorjai G A. J Phys Chem B, 2006, 110:17925

[18] Bratlie K M, Lee H, Komvopoulos K, Yang P D, Somorjai G A. Nano Lett, 2007, 7: 3097

[19] Chen J Y, Lim B, Lee E P, Xia Y N. Nano Today, 2009, 4: 81

[20] Peng Zh M, Yang H. Nano Today, 2009, 4: 143

[21] Niu W X, Xu G B. Nano Today, 2011, 6: 265

[22] Xie X W, Li Y, Liu Z Q, Haruta M, Shen W J. Nature, 2009, 458: 746

[23] Zheng Y H, Cheng Y, Wang Y Sh, Bao F, Zhou L H, Wei X F, Zhang Y Y, Zheng Q.J Phys Chem B, 2006, 110: 3093

[24] Leng M, Liu M Zh, Zhang Y B, Wang Zh Q Yu Ch, Yang X G, Zhang H J, Wang Ch. J Am Chem Soc, 2010, 132: 17084

[25] Kuo C H, Huang M H. Nano Today, 2010, 5: 106

[26] Trovarelli A. Catalysis by ceria and related materials. In: Hutchings G J ed. Catalytic Science Series. London: Imperial College Press, 2002

[27] Mai H X, Sun L D, Zhang Y W, Si R, Feng W, Zhang H P, Liu H Ch, Yan Ch H.J Phys Chem B, 2005, 109: 24380

[28] Sayle T X T, Parker S C, Catlow C R A. Surf Sci, 1994, 316: 329

[29] Sayle D C, Maicaneanu S A, Watson G W. J Am Chem Soc, 2002, 124: 11429

[30] Jiang Y, Adams J B, van Schilfgaarde M. J Chem Phys, 2005, 123: 064701

[31] Zhou K B, Wang X, Sun X M, Peng Q, Li Y D. J Catal, 2005, 229: 206

[32] Tana, Zhang M L, Li J, Li H J, Li Y, Shen W J. Catal Today, 2009, 148: 179

[33] Si R, Flytzani-Stephanopoulos M. Angew Chem, Int Ed, 2008, 47: 2884

[34] Han W Q, Wen W, Hanson J C, Teng X W, Marinkovic N, Rodriguez ] A.J Phys Chem C, 2009, 113: 21949

[35] Boucher M B, Goergen S, Yi N, Flytzani-Stephanopoulos M. Phys Chem Chem Phys, 2011, 13: 2517

[36] Li F, Hoang D T, Tsung C K, Huang W Y, Lo S H Y, Wood J B, Wang H T, Tang J Y, Yang P D. Nano Res, 2011, 4: 61

[37] Agarwal S, Lefferts L, Mojet B L. ChemCatChem, 2013, 5: 479

[38] Wang Z L, Feng X D. J Phys Chem B, 2003, 107: 13563

[39] Yang S W, Gao L. J Am Chem Soc, 2006, 128: 9330

[40] Xu J X, Li G Sh, Li L P. Mater Res Bull, 2008, 43: 990

[41] Wang T, Sun D Ch. Mater Res Bull, 2008, 43: 1754

[42] Wang D Sh, Xie T, Peng Q, Zhang Sh Y, Chen J, Li Y D. Chem Eur J, 2008, 14: 2507

[43] Yuan Q, Duan H H, Li L L, Sun L D, Zhang Y W, Yan Ch H. J Colloid Interface Sci, 2009, 335: 151

[44] Feng W, Sun L D, Zhang Y W, Yan Ch H. Coord Chem Rev, 2010, 254: 1038

[45] Zhang D S, Du X J, Shi L Y, Gao R H. Dalton Trans, 2012, 41: 14455

[46] Tyrsted C, Jensen K M O, Bojesen E D, Lock N, Christensen M, Billinge S J L, Brummerstedt B. Angew Chem, Int Ed, 2012, 51: 9030
[47] Sun C W, Li H, Chen L Q. Energy Environ Sci, 2012, 5: 8475

[48] Kaneko K, Inoke K, Freitag B, Hungria A B, Midgley P A, Hansen T W, Zhang J, Ohara S, Adschiri T. Nano Lett, 2007, 7: 421

[49] Yang Zh Q, Zhou K B, Liu X W, Tian Q, Lu D Y, Yang S. Nanotechnology, 2007, 18: 185606

[50] Lin M, Fu Z Y, Tan H R, Tan J P Y, Ng S C, Teo E. Cryst Growth Des, 2012, 12: 3296

[51] Qian L W, Zhu J, Du W M, Qian X F. Mater Chem Phys, 2009, 115: 835

[52] Dang F, Kato K, Imai H, Wada S, Haneda H, Kuwabara M. Cryst Growth Des, 2010, 10: 4537

[53] Wang X, Jiang Zh Y, Zheng B J, Xie Zh X, Zheng LS. CrystEngComm, 2012, 14: 7579

[54] Lv J G, Shen Y, Peng L M, Guo X F, Ding W P. Chem Commun, 2010, 46: 5909

[55] Zhang J, Kumagai H, Yamamura K, Ohara S, Takami S, Morikawa A, Shinjoh H, Kaneko K, Adschiri T, Suda A. Nano Lett, 2011, 11: 361

[56] Taniguchi T, Katsumata K, Omata S, Okada K, Matsushita N. Cryst Growth Des, 2011, 11: 3754

[57] Lin K S, Chowdhury S. Int J Mol Sci, 2010, 11:3226

[58] Gao F, Lu Q Y, Komarneni S. J Nanosci Nanotechnol, 2006, 6: 3812

[59] Tang B, Zhuo L H, Ge J Ch, Wang G L, Shi Zh Q, Niu J Y. Chem Commun, 2005: 3565

[60] Pan Ch S, Zhang D S, Shi L Y, Fang J H. Eur J Inorg Chem, 2008: 2429

[61] Wang W, Howe J Y, Li Y, Qiu X F, Joy D C, Paranthaman M P, Doktycz M J, Gu B. J Mater Chem, 2010, 20: 7776

[62] Bugayeva N, Robinson J. Mater Sci Technol, 2007, 23: 237

[63] Chen H L, Zhu H Y, Wang H, Dong L, Zhu J J.J Nanosci Nanotechnol, 2006, 6: 157

[64] Cerovic L, Lair V, Lupan O, Cassir M, Ringuede A. Chem Phys Lett, 2010, 494: 237

[65] Yu T, Joo J, Park Y I, Hyeon T. Angew Chem, Int Ed, 2005, 44: 7411

[66] Lin H L, Wu Ch Y, Chiang R K. J Colloid Interface Sci, 2010, 341: 12

[67] Yang Y F, Jin Y Zh, He H P, Ye Zh Zh. CrystEngComm, 2010, 12: 2663

[68] Martin P, Parker S C, Sayle D C, Watson G W. Nano Lett, 2007, 7: 543

[69] Zhang D S, Fu H X, Shi L Y, Fang J H, Li Q. J Solid State Chem, 2007, 180: 654

[70] Zhang D S, Pan Ch S, Shi L Y, Huang L, Fang J H, Fu H X. Microporous Mesoporous Mater, 2009, 117: 193

[71] Gonzalez-Rovira L, Sanchez-Amaya J M, Lopez-Haro M, del Rio E, Hungria A B, Midgley P, Calvino J J, Bernal S, Botana F J. Nano Lett, 2009, 9: 1395

[72] Chen G Zh, Sun S X, Sun X, Fan W L, You T. Inorg Chem, 2009, 48: 1334

[73] Wu X Sh, Kawi S. Cryst Growth Des, 2010, 10: 1833

[74] Chen G Zh, Xu C X, Song X Y, Zhao W, Ding Y, Sun S X. Inorg Chem, 2008, 47: 723

[75] Zhou K B, Yang Zh Q, Yang S. Chem Mater, 2007, 19: 1215

[76] Tang Ch Ch, Bando Y, Liu B D, Golberg D. Adv Mater, 2005, 17: 3005

[77] Han W Q, Wu L J, Zhu Y M. J Am Chem Soc, 2005, 127: 12814

[78] Mercadelli E, Ghetti G, Sanson A, Bonelli R, Albonetti S. Ceram Inter, 2013, 39: 629

[79] Pan Ch S, Zhang D S, Shi L Y.J Solid State Chem, 2008, 181: 1298

[80] Ivanov V K, Polezhaeva O S. Russ J Inorg Chem, 2009, 54: 1528

[81] Wang D Y, Kang Y J, Doan-Nguyen V, Chen J, Küngas R, Wieder N L, Bakhmutsky K, Gorte R J, Murray C B. Angew Chem, Int Ed, 2011, 50: 4378

[82] Yu R B, Yan L, Zheng P, Chen J, Xing X R. J Phys Chem C, 2008, 112: 


\section{Graphical Abstract}

Chin. J. Catal., 2013, 34: 838-850 doi: 10.1016/S1872-2067(12)60573-7

Tuning the shape of ceria nanomaterials for catalytic applications

TA Na, LIU (Jimmy) Jingyue*, SHEN Wenjie*

Dalian Institute of Chemical Physics, Chinese Academy of Sciences, China; Arizona State University, USA

The catalytic performance of $\mathrm{CeO}_{2}$ materials can be adjusted via tuning their shape at nanometer level by exposing different crystal planes, which influences both reaction pathway and metal-support interaction.

19896

[83]Zhong L Sh, Hu J S, Cao A M, Liu Q, Song W G, Wan L J. Chem Mater, 2007, 19: 1648

[84] Li J F, Lu G Zh, Li H F, Wang Y Q, Guo Y, Guo Y L. J Colloid Interface Sci, 2011, 360: 93

[85]Zhang D S, Niu F H, Yan T T, Shi L Y, Du X J, Fang J H. Appl Surf Sci, 2011, 257: 10161

[86]Yang Zh J, Liu L, Liang H, Yang H X, Yang Y Zh. J Cryst Growth, 2010, 312: 426

[87] Song Y T, Wei J J, Yang Y Zh, Yang Zh J, Yang H X. J Mater Sci, 2010, 45: 4158

[88] Chen G Zh, Zhu F F, Sun X, Sun S X, Chen R P. CrystEngComm, 2011, 13: 2904

[89]Chen G Zh, Xu C X, Song X Y, Xu Sh L, Ding Y, Sun S X. Cryst Growth Des, 2008, 8: 4449

[90] Bond G C, Thompson D T. Gold Bull, 2000, 33(2): 41

[91]Lopez N, Janssens T V W, Clausen B S, Xu Y, Mavrikakis M, Bligaard T, Norskov J K. J Catal, 2004, 223: 232

[92] Stephen A, Hashmi A S K, Hutchings G J. Angew Chem, Int Ed, 2006, 45: 7896

[93] Haruta M. Catal. Today, 1997, 36: 153

[94] Sandoval A, Gomez-Cortes A, Zanella R, Diaz G, Saniger J M. J Mol Catal A, 2007, 278: 200

[95] Campbell C T, Sharp J C, Yao Y X, Karp E M, Silbaugh T L. Faraday Discuss, 2011, 152: 227

[96] Andreeva D, Ivanov I, Ilieva L, Abrashev M V. Appl Catal A, 2006, 302: 127

[97]Rodriguez J A, Ma S, Liu P, Hrbek J, Evans J, Pérez M. Science, 2007, 318: 1757

[98] Baron M, Bondarchuk O, Stacchiola D, Shaikhutdinov S, Freund H J. J Phys Chem C, 2009, 113: 6042

[99]Carrettin S, Concepcion P, Corma A, Lopez Nieto J M, Puntes V F. Angew Chem, Int Ed, 2004, 43: 2538

[100] Huang P X, Wu F, Zhu B L, Gao X P, Zhu H Y, Yan T Y, Huang W P, Wu S H, Song D Y.J Phys Chem B, 2005, 109: 19169

[101] Huang X S, Sun H, Wang L C, Liu Y M, Fan K N, Cao Y. Appl Catal B, 2009, 90: 224

[102] Niu F H, Zhang D S, Shi L Y, He X Q, Li H R, Mai H L, Yan T T. Mater Lett, 2009, 63: 2132

[103]Yi G Q, Xu Zh N, Guo G C, Tanaka K, Yuan Y Zh. Chem Phys Lett, 2009, 479: 128

[104]Yi G Q, Yang H W, Li B D, Lin H Q Tanaka K, Yuan Y Zh. Catal To- day, 2010, 157: 83

[105] Yuan Zh Y, Idakiev V, Vantomme A, Tabakova T, Ren T Zh, Su B L. Catal Today, 2008, 131: 203

[106] Yi N, Si R, Saltsburg H, Flytzani-Stephanopoulos M. Appl Catal B, 2010, 95: 87

[107]Yi N, Si R, Saltsburg H, Flytzani-Stephanopoulos M. Energy Environ Sci, 2010, 3: 831

[108]Zhang Ch J, Michaelides A, Jenkins S J. Phys Chem Chem Phys, 2011, 13: 22

[109] Farmer J A, Campbell C T. Science, 2010, 329: 933

[110] Esch F, Fabris S, Zhou L, Montini T, Africh C, Fornasiero P, Comelli G, Rosei R. Science, 2005, 309: 752

[111] Liu X W, Zhou K B, Wang L, Wang B Y, Li Y D. J Am Chem Soc, 2009, 131: 3140

[112] Guan Y J, Ligthart D A J M, Pirgon-Galin O, Pieterse J A Z, van Santen R A, Hensen E J M. Top Catal, 2011, 54: 424

[113] Tana, Wang F G, Li H J, Shen W J. Catal Today, 2011, 175: 541

[114] Liu J Y. ChemCatChem, 2011, 3: 934

[115] Akita T, Okumura M, Tanaka K, Kohyama M, Haruta M. Catal Today, 2006, 117: 62

[116] Akita T, Tanaka K, Kohyama M. J Mater Sci, 2008, 43: 3917

[117] Majimel J, Lamirand-Majimel M, Moog I, Feral-Martin C, Trëguer-Delapierre M.J Phys Chem C, 2009, 113: 9275

[118] Akita T, Tanaka S, Tanaka K, Kohyama M. Mater Sci Forum, 2010, 654-656: 2362

[119] Akita T, Tanaka S, Tanaka K, Haruta M, Kohyama M. J Mater Sci, 2011, 46: 4384

[120] Uchiyama T, Yoshida H, Kuwauchi Y, Ichikawa S, Shimada S, Haruta M, Takeda S. Angew Chem Int Ed, 2011, 50: 10157

[121] Yoshida H, Kuwauchi Y, Jinschek J R, Sun K, Tanaka S, Kohyama M, Shimada S, Haruta M, Takeda S. Science, 2012, 335: 317

[122] Ta N, Liu J Y, Chenna S, Crozier P A, Li Y, Chen A, Shen W J. J Am Chem Soc, 2012, 134: 20585

[123] Sayle D C, Feng X D, Ding Y, Wang Zh L, Sayle T X T. J Am Chem Soc, 2007, 129: 7924

[124] Weststrate C J, Resta A, Westerström R, Lundgren E, Mikkelsen A, Andersen J N.J Phys Chem C, 2008, 112: 6900

[125] Chen Y, Hu P, Lee M H, Wang H F. Surf Sci, 2008, 602: 1736

[126] Fronzi M, Soon A, Delley B, Traversa E, Stampfl C. J Phys Chem C, 2009, 131: 104701

[127] Naya K, Ishikawa R, Fukui K. J Phys Chem C, 2009, 113: 10726

[128] Zhu W J, Zhang J, Gong X Q Lu G Zh. Catal Today, 2011, 165: 19 
[129] Chen Y Ch, Chen K B, Lee Ch Sh, Li M C. J Phys Chem C, 2009, 113: 5031

[130] Chen W T, Chen K B, Wang M F, Weng Sh F, Lee Ch Sh, Lin M C. Chem Commun, 2010, 46: 3286

[131] Acuna L M, Munoz F F, Cabezas M D, Lamas D G, Leyva A G, Fantini M C A, Baker R T, Fuentes R O.J Phys Chem C, 2010, 114: 19687

[132] Li H J, Qi G Sh, Tana, Zhang X J, Li W, Shen W J. Catal Sci Technol,
2011, 1: 1677

[133] Gupta K, Bhattacharya S, Chattopadhyay D, Mukhopadhyay A, Biswas H, Dutta J, Ray N R, Ghosh U C. Chem Eng J, 2011, 172: 219 [134] Li G Sh, Zhang D Q, Yu J C. Phys Chem Chem Phys, 2009, 11: 3775 [135] Reddy B M, Reddy G K, Ganesh I, Ferreira J M F. J Mater Sci 2009, 44: 2743

[136] Watanabe S, Ma X L, Song Ch Sh.J Phys Chem C, 2009, 113: 14249

\title{
基于催化应用调控氧化铈纳米材料的形貌
}

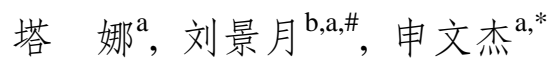 \\ a 中国科学院大连化学物理研究所催化基础国家重点实验室, 辽宁大连116023 \\ 严利桑那州立大学物理系, 亚利桑那滕比85287, 美国
}

摘要: 催化剂的设计、合成和结构调控是获得优异性能的关键. 传统的策略主要是尽量减小催化剂颗粒尺寸以增加活性中心的 数目, 即尺寸效应. 近年来, 材料科学的快速发展使得在纳米尺度上调变催化剂的尺寸和形貌成为可能, 特别是通过形貌调控可 暴露更多的高活性晶面, 大幅度提高催化性能, 即纳米催化中的形貌效应. 因此, 调节催化剂的尺寸与形貌可以单独或协同优化 材料的性能. 氧化铈作为催化剂的重要组分与结构、电子促进剂被广泛应用于多相催化剂体系. 本文总结了近期氧化铈材料形貌 可控合成的进展, 包括主要的合成策略和表征方法; 进而分析了氧化铈和金-氧化铈催化材料的形貌效应, 指出金-氧化铈之间独 特的相互作用与载体形貌密切相关; 阐述了氧化铈纳米材料因暴露晶面的差异而获得不同催化性能的化学机制.

关键词: 二氧化铈; 纳米棒; 纳米管; 纳米立方体; 形貌效应; 金-氧化铈界面

收稿日期: 2013-02-21. 接受日期: 2013-03-21. 出版日期: 2013-05-20.

*通讯联系人. 电话: (0411)84379085; 传真: (0411)84694447; 电子信箱: shen98@dicp.ac.cn

通讯联系人. 电话/传真: +01-480-965-9731; 电子信箱: jingyue.liu@asu.edu

基金来源：国家自然科学基金(20923001, 21025312和21103172).

本文的英文电子版由Elsevier出版社在ScienceDirect上出版(http://www.sciencedirect.com/science/journal/18722067). 